\title{
Is There a Standard Adjuvant Therapy for Resected Pancreatic Cancer?
}

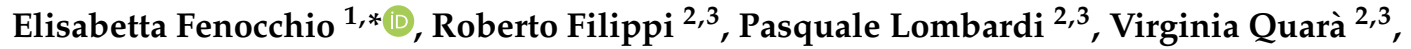 \\ Michela Milanesio 2,3, Giacomo Aimar 2,3, Francesco Leone ${ }^{3,4}$ and Massimo Aglietta 2,3 \\ 1 Multidisciplinary Outpatient Oncology Clinic, Candiolo Cancer Institute, FPO-IRCCS, \\ Strada Provinciale 142, km 3.95, 10060 Candiolo (TO), Italy \\ 2 Department of Oncology, University of Turin Medical School, Strada Provinciale 142, km 3.95, \\ 10060 Candiolo (TO), Italy; roberto.filippi@ircc.it (R.F.); pasquale.lombardi@ircc.it (P.L.); \\ virginia.quara@ircc.it (V.Q.); michela.milanesio@ircc.it (M.M.); giacomo.aimar@ircc.it (G.A.); \\ massimo.aglietta@unito.it (M.A.) \\ 3 Division of Medical Oncology, Candiolo Cancer Institute, FPO-IRCCS, Strada Provinciale 142, km 3.95, \\ 10060 Candiolo (TO), Italy; francesco.leone@unito.it \\ 4 Department of Oncology, Azienda Sanitaria Locale di Biella, 13875 Ponderano (BI), Italy \\ * Correspondence: elisabetta.fenocchio@ircc.it; Tel.: +39-011-9933628; Fax: +39-011-9933275
}

Received: 16 September 2019; Accepted: 11 October 2019; Published: 12 October 2019

\begin{abstract}
Surgical resection remains the only treatment that offers a potential chance of long-term survival. Unfortunately, about $80 \%$ of patients treated with curative intent will develop recurrence. Since 2001, adjuvant therapy with gemcitabine or 5-fluorouracyle was recommended. This approach allows a median overall survival (OS) of around 23 months, and 5-year survival of $22 \%$. In recent years, two phase- 3 trials investigating new chemotherapy regimens resulted in considerably improved survival times. The doublet gemcitabine-capecitabine has shown improvement in OS from 25.5 to 28 months $(p=0.032)$ compared to gemcitabine, in the ESPAC-4 trial. Later, preliminary results of PRODIGE 24 trial presented at the 2018 ASCO meeting showed a superiority of a combination chemotherapy regimen with fluorouracil, leucovorin, irinotecan, and oxaliplatin (mFOLFIRINOX) when compared to gemcitabine alone, both in terms of median disease-free survival (21.6 vs. 12.8 months, $p<0.0001)$ and OS (54.4 vs. 35 months, $p=0.003)$. Contrary to chemotherapy, the role of adjuvant radiotherapy is still controversial, even in the case of R1 surgery. A randomized trial exploring the role of chemoradiotherapy in this setting is now ongoing in the US (RTOG-0848). Overall, the management of localized pancreatic adenocarcinoma is evolving. In this review, we summarize the current status and the most up-to-date developments in adjuvant treatment.
\end{abstract}

Keywords: adjuvant chemotherapy; adjuvant chemoradiation; pancreatic ductal carcinoma; capecitabine; gemcitabine; mFOLFIRINOX

\section{Introduction}

Pancreatic ductal adenocarcinoma (PDAC) is characterized by dismal prognosis, with the lowest survival rate of all the common malignancies worldwide, with an estimated 5-year (y) survival rate of $<5 \%$ [1].

Responsible for over 95,000 deaths every year in Europe, PDAC is the third-leading cause of cancer-related death, behind lung and colorectal cancer, and it is expected to become the second-leading cause of cancer death by 2020 [2].

Despite recent advances in immunotherapy and perioperative therapy, resulting in more successful resections and targeted treatments, PDAC mortality has steadily risen over the past few decades [3-5]. 
For early-stage PDAC, surgical resection with negative margins represents the treatment option with the best chances of long-term survival, but outcomes remain poor. Among the $20 \%$ of patients (pts) diagnosed with a localized PDAC, the disease recurs in up to $80 \%$ within 2 years [6-8].

Therefore, an adjuvant treatment has been advocated to increase the percentage of pts with long-term survival after surgery. Multiple clinical trials previously investigated the clinical outcomes of diverse adjuvant therapy regimens. However, the optimal multidisciplinary treatment strategy is still controversial.

We hereby review the evidence on current and investigational adjuvant treatments for PDAC. Eligible studies were identified using PubMed electronic database for full manuscripts; abstracts and posters from conferences of international scientific societies were interrogated as well.

\section{Chemotherapy}

Historically, the first randomized trial evaluating adjuvant chemotherapy (CT) in resected PDAC was conducted back in the 1980s. Among 61 pts with resected pancreatic $(n=47)$ or ampullary cancer, post-operatory AMF (5-fluorouracil (5FU), doxorubicin, mitomycin $\mathrm{C}$ ) regimen increased overall survival (OS) to 23 months from 11 months observed in the arm that did not receive adjuvant CT ( $p$ 0.04). However, this benefit was short-lived, and as early as at two years after randomization no difference in OS could be detected between arms ( $p$ 0.10). Even though the cure rate was not improved, this trial provided the proof of concept that adjuvant $\mathrm{CT}$ was able to impact on the disease course, and specifically by delaying the occurrence of disease relapse [9].

As the first adequately powered randomized trial evaluating adjuvant therapy in PDAC, the European Study Group for Pancreatic Cancer (ESPAC)-1 trial is considered a landmark study. It was characterized by a two-by-two factorial design, according to which each patient randomly received 5FU-based chemoradiation therapy (CRT) consisting of 20 Gy administered in 10 daily fractions, 6-month bolus 5FU-based CT, neither treatment, or both treatments administered sequentially. $289 \mathrm{pts}$ were allocated to the treatment arms. OS was 20.1 months (confidence interval (CI)95\% 16.5-22.7) among the 147 pts that received CT and 15.5 months (CI95\% 13.0-17.7) among the 142 pts who did not (hazard ratio (HR) 0.71, CI95\% $0.55-0.92 ; p 0.009$ ); 5 -y OS rates were $21 \%$ and $8 \%$, respectively. The beneficial role of CT was independent of CRT receipt. Median (5-y rate) OS was 16.9 months $(11 \%)$ among pts subject to observation, 13.9 months (7\%) among pts treated with CRT, 21.6 (29\%) with CT, and 19.9 months (13\%) with CT-CRT [10]. The beneficial role of 5FU was later confirmed by a metanalysis of ESPAC-1 with other two trials of the ESPAC series (HR 0.70, CI95\% 0.55-0.88) [11].

Gemcitabine (GEM), to this day the pivotal drug in the treatment of PDAC, was introduced into the adjuvant setting in the phase-3 Charite Onkologie (CONKO)-001 trial, in which 368 pts were randomly allocated to receive either GEM $\left(1000 \mathrm{mg} / \mathrm{m}^{2}\right.$ days $1,8,15 / 28$ days for 6 cycles) or observation. Median disease-free survival (DFS) was doubled by GEM (13.4 months vs. 6.7 in the control arm $p<0.001)$; the beneficial role was consistent across all predefined strata, i.e., tumor stage, nodal status, and resection status. The benefit remained significant in the OS analysis (22.8 months vs. 20.2, HR 0.76 (CI95\%, 0.61-0.95); $p 0.01 ; 5$-y OS 20.7\% vs. $10.4 \%$ ), although GEM could be received by relapsed pts in the control arm [12,13]. The CONKO-001 trial established a 6-month course of GEM as the standard of care for more than a decade. Its schedule for GEM administration would serve as model in the subsequent trials.

Similarly, GEM showed an advantage in terms of DFS even in the Asian population as suggested in the study by Ueno et al. [14] In a scenario where the beneficial role of adjuvant CT for surgically resected PDAC seemed to be established and both 5FU and GEM had proven effective in the adjuvant setting, the phase-3 ESPAC-3 (version 2) trial was designed to compare both regimens: 1088 pts were postoperatively randomized to either 5FU or GEM. No statistically significant difference was highlighted in both OS and DFS between treatment arms: OS was 23.0 months with 5FU (CI95\% 21.1-25.0) vs. 23.6 with GEM (CI95\% 21.4-26.4), and progression free survival (PFS) 14.1 months (CI95\% 12.5-15.3) vs. 14.3 months (CI95\% 13.5-15.6), respectively. However, serious adverse events were less 
prevalent in the GEM arm $(7.5 \%)$ than in the 5FU arm $(14 \%)(p<0.001)$. Based on the better safety profile, GEM became the standard of care in the adjuvant treatment of surgically resected PDAC [15].

Adjuvant monotherapy could ensure long-term survival to only 16-21\% pts, up until 2017, when the phase-3 ESPAC-4 trial provided the first significant move out of a years-long impasse. The doublet GEM plus capecitabine had previously shown better activity and efficacy than GEM alone in advanced PDAC, while maintaining an acceptable toxicity profile [16-18]. In the ESPAC-4 trial, 730 pts were randomly allocated to receive adjuvant GEM alone or in association with oral capecitabine $\left(830 \mathrm{mg} / \mathrm{m}^{2}\right.$ twice a day on days 1-21/28) for 6 cycles. After a median follow-up time of 43 months, OS was modestly prolonged by the addition of capecitabine to 28.0 months (CI95\% 23.5-31.5) vs. 25.5 (CI95\% 22.7-27.9) in the control arm, resulting in a clinically modest HR 0.82 (CI95\% 0.68-0.98, $p 0.032)$. As survival curves tended to a late separation, 5 -y OS was improved ( $28.8 \%$ vs. $16.3 \%$, respectively) but the OS difference at 2 years was less than $2 \%$. The benefit from the combination treatment appeared confined to pts who underwent R0 resections (39.5 months vs. 27.9, $p<0.001$ ), as opposed to those with R1 resections ( 23.7 vs. 23.0 months, p ns). Recent findings from a secondary analysis of this trial showed no significant differences between the time to recurrence and subsequent and OS between local and distant recurrence [19]. The study population of the ESPAC-4 trial was characterized by a worse prognostic profile than prior studies, highlighted by the high rate of pts with elevated post-operative blood carbohydrate antigen 19-9 (CA19.9) levels, tumor grade (G) 3 and lymph node (N) positivity, and reflected in the low survival observed in the control arm (5-y OS 16.3\%), as compared to CONKO-001. This feature underscores the potential applicability of the ESPAC-4 findings to the real-life scenario. As for the safety profiles, the addition of capecitabine increased the incidence of G3- 4 diarrhea ( $5 \% \mathrm{vs}$. $2 \%, p 0.008$ ), neutropenia ( $38 \%$ vs. $24 \%, p<0.001$ ), and hand-foot syndrome ( $7 \%$ vs. $0 \%, p<0.001$ ), but the proportion of pts experiencing G3-4 adverse events was similar between arms [20]. As a result, the combination of GEM plus capecitabine for 6 months was established as the new standard of care following resection for PDAC, translating the improvements in tumor response and disease control obtained in advanced PDAC into the adjuvant landscape.

Shifting focus on experimental research conducted on Asian population, the phase-3 Japan Adjuvant Study Group of Pancreatic Cancer (JASPAC)-01 trial compared oral S-1 vs. GEM. 385 pts with an Eastern Cooperative Oncology Group performance status (ECOG PS) of 0 or 1 to receive a 6-month course of GEM or S-1 (40-60 mg on the basis of body surface area twice daily, 4 weeks on and 2 weeks off). OS was markedly prolonged in S-1 arm (46.5 vs. 25.5 months in control arm, HR 0.57, CI95\% 0.44-0.72, $p<0.001$ ). Moreover, S-1 exhibited a more favorable toxicity profile, with lower incidence of G3-4 leukopenia, neutropenia and transaminase elevation, and was associated with a higher quality of life than GEM. An intrinsic limitation of the study is that superiority of S-1 was not tested in the intention-to-treat but in the per-protocol population only [21]. Moreover, considering the reported differences existing in the pharmacokinetics and pharmacodynamics between Asian and Caucasian pts, it is difficult to assume that S-1 is universally superior to GEM, thus the results cannot be extended to the Western population.

The CONKO-005 trial, which found its scientific supportive background in the modest efficacy observed for the addition of erlotinib in the advanced disease [22], was the first phase-3 trial to investigate the adjuvant combination of a targeted agent with a classic cytostatic drug (i.e., GEM). This was a negative trial, in which a difference in DFS was not found (11.4 months in both arms, HR 0.94, CI95\% 0.76-1.15, $p$ ns) [23]. Ongoing analysis of tumor tissue samples of the CONKO-005 trial will hopefully identify a molecular subset of pts for whom Epidermal growth factor receptor (EGFR) inhibition provides maximum benefit. Similarly, the addition of sorafenib did not improve survival in R1-resected pts (CONKO-006 trial) [24].

More recently, the phase-3 PRODIGE 24-ACCORD 24-CCTG PA 6 trial investigated adjuvant mFOLFIRINOX, once again a regimen adopted from the advanced setting. In this trial 493 pts were randomly allocated to receive either a 6-month course of biweekly modified FOLFIRINOX (oxaliplatin $85 \mathrm{mg} / \mathrm{m}^{2}$, leucovorin $400 \mathrm{mg} / \mathrm{m}^{2}$, irinotecan $150 \mathrm{mg} / \mathrm{m}^{2}$ after an initial dose of $180 \mathrm{mg} / \mathrm{m}^{2}, 5 \mathrm{FU}$ 
$2400 \mathrm{mg} / \mathrm{m}^{2}$ over $46 \mathrm{~h}$ ), or GEM. The primary endpoint DFS was significantly prolonged, by 8.8 months, in the mFOLFIRINOX arm with respect to GEM (21.6 vs. 12.8 months, respectively; stratified HR 0.58 , CI95\% 0.46-0.73, $p<0.001)$. Remarkably, the DFS benefit with mFOLFIRINOX was significant in most subgroups, including those with adverse prognostic factors (e.g., T3 or T4 tumor, positive lymph nodes, or R1 resection). Pts allocated to the experimental arm experienced OS of 54.4 months vs. 35.0 in control arm (HR 0.64, CI95\% 0.48-0.86, $p$ 0.003), at the price of increased toxicity: mFOLFIRINOX treatment was associated with significantly higher incidence of G3-4 diarrhea, $\gamma$-glutamyl transferase increased, paresthesia, sensory peripheral neuropathy, fatigue, nausea, emesis, abdominal pain, and mucositis. Furthermore, in this trial a World Health Organisation performance status of 0 or 1 was an eligibility criterion, thus the observed difference in efficacy might have been magnified by the patient selection. Importantly, while the trial enrolled pts up to 79 years of age, and subgroup analysis showed no difference of effect between pts younger and older than 65 , pts with at least 70 years of age did not gain any benefit from mFOLFIRINOX over GEM [25]. With these precautions, mFOLFIRINOX conferred an undisputable benefit to pts radically resected for PDAC and is poised to be the new standard of adjuvant care, or at least a viable therapeutic option, in fit pts with negligible comorbidity background and good recovery from surgery (Table 1). 
Table 1. OS outcomes of the published randomized, controlled trials of adjuvant CT in PDAC.

\begin{tabular}{|c|c|c|c|c|c|c|c|c|}
\hline \multirow{2}{*}{$\begin{array}{l}\text { Trial, Year of Publication; } \\
\text { n; Geographical Region }\end{array}$} & \multirow{2}{*}{ Treatment Arms } & \multicolumn{2}{|c|}{ Study Population } & \multicolumn{3}{|c|}{ OS } & \multicolumn{2}{|c|}{ Subgroups } \\
\hline & & No & Ro & Median (mts) & $\mathrm{HR}, p$ & $\begin{array}{c}\text { 5-Year Rate (Actual or } \\
\text { Estimated) }\end{array}$ & Nodal Involvement & Resection Margins \\
\hline $\begin{array}{l}\text { Bakkevold et al., } 1993 \text { [9]; } \\
61 \text { (77\% PDAC); Western }\end{array}$ & $\begin{array}{l}\text { Dox, MMC, } 5 \mathrm{FU} \text { (6 cycles) } \\
\text { vs. Obs }\end{array}$ & na & na & 23 vs. 11 & $p 0.02$ & $4 \%$ vs. $8 \%, p 0.6$ & na & na \\
\hline \multirow{2}{*}{$\begin{array}{l}\text { Takada et al., } 2002 \text { [26]; } 436 \\
\quad(36 \% \text { PDAC); Eastern }\end{array}$} & \multirow{2}{*}{$\begin{array}{l}\text { MMC, 5FU (2 cycles) vs. } \\
\text { Obs }\end{array}$} & \multicolumn{7}{|c|}{ PDAC } \\
\hline & & $20 \%$ & $58 \%$ & na & na, $p$ ns & $11.5 \%$ vs. $18.0 \%$ & na & $\begin{array}{l}\mathrm{R} 0: p 0.45 \\
\mathrm{R}+: p 0.75\end{array}$ \\
\hline \multirow{2}{*}{$\begin{array}{c}\text { ESPAC-1 and exp, } 2004 \text { and } \\
2001 \text { [10,27]; } 289 \text { and 541; } \\
\text { Western }\end{array}$} & \multirow{2}{*}{$\begin{array}{l}\text { CT (LV, 5FU; } 6 \text { cycles) vs. } \\
\text { CRT (20 Gy/10 fr, 5FU) vs. } \\
\text { CRT + CT vs. Obs }\end{array}$} & \multirow{2}{*}{$\begin{array}{l}41 \% 47 \% \\
(\exp )\end{array}$} & \multirow{2}{*}{$\begin{array}{l}82 \% 81 \% \\
(\exp )\end{array}$} & \multicolumn{5}{|c|}{ CT vs. no CT } \\
\hline & & & & 20.1 vs. 15.5 & $\begin{array}{l}0.71(0.55-0.92) \\
\quad p 0.009\end{array}$ & $21 \%$ vs. $8 \%$ & Phet 0.50 & $\begin{array}{c}\text { R0: } 20.7 \text { vs. } 15.3, \text { HR } 0.65 \\
(0.52-0.83) \text { R1: } 11.0 \text { vs. } \\
10.3, p \text { ns }\end{array}$ \\
\hline $\begin{array}{l}\text { Kosuge et al., } 2006 \text { [28]; 89; } \\
\text { Eastern }\end{array}$ & $\begin{array}{c}\text { Cis, } 5 \mathrm{FU} \text { ( } 2 \text { cycles }) \text { vs. } \\
\text { Obs }\end{array}$ & $24 \%$ & $100 \%$ & 12.5 vs. 15.8 & $p 0.94$ & $26.4 \%$ vs. $14.9 \%$ & na & na \\
\hline $\begin{array}{c}\text { CONKO-001, } 2007[12,13] \\
\text { 368; Western }\end{array}$ & Gem (6 cycles) vs. Obs & $28 \%$ & $83 \%$ & 22.8 vs. 20.2 & $\begin{array}{c}0.76(0.61-0.95) \\
\quad p 0.01\end{array}$ & $20.7 \%$ vs. $10.4 \%$ & $\begin{array}{c}\text { N0: } 34.0 \text { vs. } 27.6 ; \text { HR } 0.63 \\
\text { (0.40-0.97), } p 0.04 \\
\text { N+: } 18.5 \text { vs. } 18.2 ; \text { HR } 0.81 \\
(0.63-1.06), p 0.44\end{array}$ & $\begin{array}{c}\text { R0: } 21.7 \text { vs. } 20.8, \mathrm{p} 0.18 ; \\
\text { HR } 0.76(0.60-0.98) \text { R1: } \\
\text { 22.1 vs. } 14.1, p 0.07 ; \text { HR } \\
0.66(0.39-1.13)\end{array}$ \\
\hline $\begin{array}{l}\text { JSAP-02, } 2009 \text { [14]; 118; } \\
\text { Eastern }\end{array}$ & Gem (3 cycles) vs. Obs & $31 \%$ & $84 \%$ & 22.3 vs. 18.4 & $\begin{array}{c}0.77(0.51-1.14) \\
p 0.19\end{array}$ & $23.9 \%$ vs. $10.6 \%$ & $\begin{array}{c}\text { N0: } 32.0 \text { vs. } 28.4 ; \text { HR } 0.63 \\
\text { (0.29-1.97), } p 0.24 \\
\text { N1: } 17.1 \text { vs. } 17.3 ; \text { HR } 0.84 \\
(0.53-1.34), p 0.44\end{array}$ & $\begin{aligned} \text { R0: } 26.8 \text { vs. } 19.1 ; \mathrm{HR} 0.70 \\
\text { (0.45-1.09), } p 0.11 \\
\text { R1: } 18.3 \text { vs. } 17.6 ; \mathrm{HR} 1.05 \\
(0.41-2.72), p 0.92\end{aligned}$ \\
\hline $\begin{array}{c}\text { ESPAC-3 v2, } 2010 \text { [15]; } \\
\text { 1088; World }\end{array}$ & $\begin{array}{l}\text { FA, } 5 \mathrm{FU} \text { ( } 6 \text { cycles }) \text { vs. } \\
\text { Gem ( } 6 \text { cycles })\end{array}$ & $28 \%$ & $65 \%$ & 23.2 vs. 23.0 & $\begin{array}{l}0.94(0.81-108) \\
\quad p 0.39\end{array}$ & $15.9 \%$ vs. $17.5 \%, p 0.39$ & phet 0.60 & Phet 0.56 \\
\hline $\begin{array}{l}\text { ESPAC-4, } 2017 \text { [20]; 732; } \\
\text { Western }\end{array}$ & $\begin{array}{l}\text { Gem, Cap (6 cycles) vs. } \\
\text { Gem (6 cycles) }\end{array}$ & $20 \%$ & $40 \%$ & 28.0 vs. 25.5 & $\begin{array}{c}0.82(0.68-0.98) \\
\quad p 0.032)\end{array}$ & $28.8 \%$ vs. $17.5 \%, p 0.032$ & na & $\begin{array}{l}\text { R0: } 39.5 \text { vs. } 27.9 \\
\text { R1: } 23.7 \text { vs. } 23.0 \\
\end{array}$ \\
\hline $\begin{array}{l}\text { JASPAC-01, } 2016 \text { [21]; 385; } \\
\text { Eastern }\end{array}$ & Gem vs. S- 1 (4 cycles) & $37 \%$ & $87 \%$ & 25.5 vs. 46.5 & $\begin{array}{r}0.57(0.44-0.72) \\
\mathrm{p}_{\mathrm{ni}} \text { and } p<0.001\end{array}$ & $\begin{array}{c}24.2 \% \text { vs. } 43.6 \% \\
\quad p<0.001\end{array}$ & $\begin{array}{l}\text { N0: HR } 0.51(0.32-0.80) \\
\text { N1: HR } 0.56(0.42-0.75)\end{array}$ & $\begin{array}{l}\text { R0: HR } 0.56(0.43-0.73) \\
\text { R1: HR 0.57 (0.30-1.08) }\end{array}$ \\
\hline $\begin{array}{l}\text { CONKO-005, } 2017 \text { [23]; 436; } \\
\text { Eastern }\end{array}$ & Gem, Erl vs. Gem & $35 \%$ & $100 \%$ & 24.5 vs. 26.5 & na, $p 0.61$ & $23 \%$ vs. $20 \%$ & no difference & - \\
\hline $\begin{array}{l}\text { PRODIGE 24, } 2018 \text { [25]; } \\
\text { 493; Western }\end{array}$ & $\begin{array}{c}\text { mFOLFIRINOX (12 } \\
\text { cycles) vs. Gem (6 cycles) }\end{array}$ & $23 \%$ & $57 \%$ & 54.4 vs. 35.0 & $\begin{array}{l}0.64(0.48-0.86) \\
\quad p 0.003\end{array}$ & na & $\begin{array}{c}\text { N0: HR } 0.89(0.53-1.49) \\
\text { N1: HR } 0.54(0.42-0.69) \\
\text { phet } 0.10\end{array}$ & $\begin{array}{c}\text { R0: HR } 0.72(0.53-0.98) \\
\text { R1: HR } 0.52(0.37-0.72) \\
\text { phet } 0.15\end{array}$ \\
\hline
\end{tabular}

Abbreviations: 5FU = 5-fluorouracil; Cap = capecitabine; Cis = cisplatin; CRT = chemoradiation therapy; CT = chemotherapy; Dox = doxorubicin; ERL = erlotinib; exp = expansion;

$\mathrm{FA}=$ folinic acid; Gem = gemcitabine; Iri = irinotecan; $\mathrm{LV}=$ leucovorin; MMC = mitomycin C; mts = months; na = not available; Obs = observation; OS = overall survival; Oxa = oxaliplatin; $\mathrm{PDAC}=$ pancreatic ductal adenocarcinoma; $\mathrm{p}_{\mathrm{het}}=\mathrm{p}$ for heterogeneity; $\mathrm{p}_{\mathrm{ni}}=\mathrm{p}$ for non-inferiority; CONKO: Charité Onkologie; JSAP: Japanese Study Group of Adjuvant Therapy for Pancreatic Cancer; ESPAC: European Study Group for Pancreatic Cancer; JASPAC: Adjuvant Study Group of Pancreatic Cancer; mFOLFIRINOX: oxaliplatin, leucovorin, irinotecan, 5-fluorouracil); PRODIGE 24: Partenariat de Recherche en Oncologie Digestive; HR: hazard ratio. 


\section{Chemoradiation Therapy}

Around one third of curatively resected PDAC pts will experience a local relapse in the absence of distant metastases $[10,19]$. The rational of integrating radiotherapy (RT) into the adjuvant therapeutic algorithm should be aimed to reduce the rate of local recurrence, which is as deadly as the metastatic spread, as eloquently demonstrated in the aforementioned ESPAC-4 trial. In this study, in which only $4 \%$ of pts received post-progression CRT [20], local recurrence was not associated with better post-progression survival compared to distant relapse [19]. However, if and how to associate RT with the widely accepted adjuvant CT option has long been matter of debate.

The potential of adjuvant CRT to improve patient survival was first showed in the 1980s by the Gastrointestinal Tumor Study Group (GITSG) 9173 study [29], in which 43 pts with resected PDCA and negative resection margins were randomized to observation or split-course CRT using 5FU as a radiosensitizer. RT was delivered to a dose of $40 \mathrm{~Gy}$ in $2 \mathrm{~Gy}$ fractions with a 2-week break after the initial 20 Gy. Despite the suboptimal radiation dose, and the low statistical power owing to the premature accrual termination due to slow accrual, the analysis of 43 treated pts revealed a statistically significant increase in OS in the CRT arm.

The survival benefit of celiac axis infusion (intra-arterial mitoxantrone, 5FU, leucovorin, and cisplatinum) combined with RT (54 Gy) versus observation after pancreatic cancer resection was investigated in a randomized controlled trial by Morak et al. [30]. No significant OS benefit was seen, but treatment schedule resulted in a prolonged time to progression.

Subsequent studies achieved conflicting results. In the phase-3 European Organization for Research and Treatment of Cancer (EORTC) 40891 trial, 218 pts with pancreatic head or periampullary adenocarcinomas were randomly assigned to split-course 5FU-based CRT (40 Gy) or observation [31,32]. No difference was observed either in terms of local relapse or OS between the two study arms. However, in this study, in which PDAC pts accounted only for a half of the study population, $50 \%$ and $20 \%$ of pts in the experimental arm did not receive $\mathrm{CT}$ per protocol or the intended adjuvant treatment at all, respectively.

In more recent times, the ESPAC 1 trial was a phase- 3 factorial trial that randomized 541 pts to observation or adjuvant treatment with CRT alone, CT alone, or CRT followed by CT. A deleterious effect on survival emerged for adjuvant CRT, with estimated 5-year OS rates halved by the treatment [10]. This was ascribed to the delay of administration of CT following CRT, reducing the potential to eradicate micrometastatic disease as a consequence. However, definitive conclusions were impeded by several important limitations, among which the different time to the start of treatment in the different arms and the inadequate RT dose.

A subsequent large, phase-3 study, the Radiation Therapy Oncology Group (RTOG) 9704 trial [33,34] compared the role of GEM versus 5FU in addition to adjuvant CRT, consisting of dose of 50.4 Gy with concurrent continuous infusion of 5FU. No difference in terms of DFS or OS between the two arms was observed. Nevertheless, in the subgroup of pancreatic head tumors ( $388 \mathrm{pts})$, a trend of OS in favor of GEM was observed ( $p$ 0.08). A subsequent analysis further underlined the role of RT, observing that pts who failed to attain full exposure to per-protocol CRT administration experienced worse OS [35].

A randomized phase-2 trial, the EORTC-40013-22012/Federation Francophone de Cancérologie Digestive (FFCD)-9203/Groupe Coopérateur Multidisciplinaire en Oncologie (GERCOR) study evaluated adding CRT to adjuvant CT versus $\mathrm{CT}$ alone. This study enrolled $90 \mathrm{pts}$ and compared two cycles of adjuvant GEM followed by CRT with concurrent weekly GEM to four cycles of adjuvant GEM The bimodal strategy proved slightly more toxic, and appeared to decrease the rate of first local recurrence ( $11 \%$ vs. $24 \%$ in the control arm), but no differences in DFS or OS were observed [36] (Table 2). 
Table 2. OS outcomes of the published randomized, controlled trials of adjuvant CRT in PDAC.

\begin{tabular}{|c|c|c|c|c|c|c|c|c|}
\hline \multirow[b]{2}{*}{$\begin{array}{l}\text { Trial, Year of Publication; } \\
\text { n; Geographical Region }\end{array}$} & \multirow[b]{2}{*}{ Treatment Arms } & \multicolumn{2}{|c|}{ Study Population } & \multicolumn{3}{|c|}{ OS } & \multicolumn{2}{|c|}{ Subgroups } \\
\hline & & No & R0 & Median (mts) & HR, $p$ & $\begin{array}{l}\text { 5-Year Rate } \\
\text { (Actual or } \\
\text { Estimated) }\end{array}$ & $\begin{array}{c}\text { Nodal } \\
\text { Involvement }\end{array}$ & $\begin{array}{l}\text { Resection } \\
\text { Margins }\end{array}$ \\
\hline $\begin{array}{c}\text { GITSG 9173, } 1985 \text { [29,37]; } \\
\text { 43; Western }\end{array}$ & $\begin{array}{c}\text { CRT (20 Gy x2, 5FU) + 5FU } \\
\text { vs. Obs }\end{array}$ & na & na & 21.0 vs. 10.9 & $p 0.03$ & $18 \%$ vs. $5 \%$ & na & na \\
\hline $\begin{array}{l}\text { EORTC 40891, } 1999 \text { [31,32]; } \\
218 \text { (PDAC 55\%); Western }\end{array}$ & CRT (40 Gy/20 fr, 5FU) & $39 \%$ & $77 \%$ & 15.6 vs. 12.0 & $\begin{array}{l}0.91(0.68-1.23) \\
\quad p 0.54\end{array}$ & $25 \%$ vs. $22 \%$ & na & na \\
\hline \multirow{2}{*}{$\begin{array}{l}\text { ESPAC- } 1 \text { and exp, } 2004 \text { and } \\
2001 \text { [10,27]; } 289 \text { and 541; } \\
\text { Western }\end{array}$} & \multirow{2}{*}{$\begin{array}{l}\text { CT (LV, 5FU; } 6 \text { cycles) vs. } \\
\text { CRT (20 Gy/10 fr, 5FU) vs. } \\
\text { CRT + CT vs. Obs }\end{array}$} & \multirow[b]{2}{*}{$\begin{array}{l}41 \% 47 \% \\
\quad(\exp )\end{array}$} & \multirow[b]{2}{*}{$\begin{array}{c}82 \% \\
81 \%(\exp )\end{array}$} & \multicolumn{5}{|c|}{ CRT vs. no CRT } \\
\hline & & & & 15.9 vs. 17.9 & $\begin{array}{c}1.28(0.99-1.66) \\
\quad p 0.05\end{array}$ & $10 \%$ vs. $20 \%$ & $\mathrm{p}_{\text {het }} 0.85$ & $\begin{array}{l}\text { R0: } 15.9 \text { vs. } 16.9, \\
\text { p ns R1: } 10.9 \text { vs. } \\
\text { 12.1, p ns }\end{array}$ \\
\hline \multirow{2}{*}{$\begin{array}{c}\text { RTOG 9704, } 2008 \text { [33,34]; } \\
\text { 451; Western }\end{array}$} & \multirow{2}{*}{$\begin{array}{c}\text { CRT }(50.4 \text { Gy/28 fr, } 5 \mathrm{FU})+ \\
\text { Gem }(1+3 \text { cycles }) \text { vs. CRT }+ \\
\text { 5FU }(1+2 \text { cycles })\end{array}$} & \multirow[b]{2}{*}{$34 \%$} & \multirow[b]{2}{*}{$42 \%$} & \multicolumn{5}{|c|}{ Pancreatic head } \\
\hline & & & & 20.5 vs. 17.1 & $\begin{array}{l}0.84(0.67-1.05) \\
p 0.12\end{array}$ & $22 \%$ vs. $18 \%$ & na & na \\
\hline $\begin{array}{l}\text { Morak et al., } 2008 \text { [30]; } 120 \\
\text { (PDAC 52\%); Western }\end{array}$ & $\begin{array}{c}\text { RT ( } 54 \text { Gy/30 fr })+ \text { i.a. Mit, } \\
\text { FA, } 5 \text { FU, Cis }(1+5 \text { cycles }) \text { vs. } \\
\text { Obs }\end{array}$ & $47 \%$ & $73 \%$ & na & $p 0.66$ & na & na & na \\
\hline $\begin{array}{l}\text { EORTC-40013-22012/FFCD- } \\
\text { 9203/GERCOR, } 2010 \text { [36]; } \\
\text { 90; Western }\end{array}$ & $\begin{array}{c}\text { Gem }(2 \text { cycles })+\text { CRT } \\
(50.4 \text { Gy/28 fr, Gem }) \text { vs. Gem } \\
\text { (4 cycles })\end{array}$ & $30 \%$ & $100 \%$ & 24.3 vs. 24.4 & na & na & na & na \\
\hline $\begin{array}{l}\text { CapRI, } 2012 \text { [38]; 110; } \\
\text { Western }\end{array}$ & $\begin{array}{c}\text { CRT (50.4 Gy/28 fr, 5FU, Cis, } \\
\text { IFN } \alpha-2 b)+5 F U(2 \text { cycles }) \text { vs. } \\
\text { FA, } 5 \text { FU ( } 6 \text { cycles })\end{array}$ & $21 \%$ & $61 \%$ & 26.5 vs. 28.5 & $\begin{array}{l}1.04(0.66-1.53) \\
\quad p 0.99\end{array}$ & na & na & na \\
\hline
\end{tabular}

Abbreviations: 5FU = 5-fluorouracil; Cis = cisplatin; CRT = chemoradiation therapy; CT, chemotherapy; FA = folinic acid; fr = fractions; Gem = gemcitabine; i.a. = intra-arterial; IFN interferon; $\mathrm{LV}=$ leucovorin; Mit = mitoxantrone; $\mathrm{mts}=$ months; $\mathrm{na}=$ not available; Obs = observation; $\mathrm{OS}=$ overall survival; $\mathrm{PDAC}=$ pancreatic ductal adenocarcinoma; $\mathrm{phet}=\mathrm{p}$ for

heterogeneity; GITSG: Gastrointestinal Tumor Study Group; EORTC: European Organization for Research and Treatment of Cancer; RTOG: Radiation Therapy Oncology Group; FFCD:

Federation Francophone de Cancérologie Digestive; GERCOR: Groupe Coopérateur Multidisciplinaire en Oncologie. 
A network meta-analysis (2013) compared efficacy and toxicity of the major adjuvant treatments (5FU, GEM, CRT, CRT and 5FU, CRT and gem). With the caveats concerning heterogeneity of the included studies, CRT plus 5FU or GEM did not seem to provide a survival advantage over CT, with an increase in toxicities; moreover, CRT alone appeared to confer no survival benefit compared to observation.

This work reinforced the suggestion against proposing adjuvant CRT to unselected pts. Specific categories of pts had to be identified that could truly benefit from the addition of CRT to adjuvant CT. Among the most recent retrospective and registry studies (Table 3), an analysis of data from $6165 \mathrm{pts}$ treated with adjuvant CT (38\%) or CRT (62\%) from the US National Cancer Database [39]. Most cases were classified as pT3 (72\%), pN1 (67\%) and R0-resected (84\%). The median dose of RT was $50.4 \mathrm{~Gy}$, whereas no details were provided concerning the CT regimens employed; included cases had RT initiated before the third cycle of CT. In addition to a small OS improvement with CRT compared to CT in the overall population, this analysis importantly circumscribed this observed benefit to pts with pT3 (HR 0.89, CI95\%, 0.83-0.96, $p$ 0.003) or pN1 (HR 0.86, CI95\%, 0.79-0.92, $p<0.001$ ) disease. On the contrary, resection margin status did not predict CRT efficacy over CT, with small gains observed both in R0 (HR 0.90, CI95\%, 0.84-0.97, p 0.005) and R1 resections (HR 0.84; CI95\%, 0.72-0.98, p 0.030). Limitations of this study include the lack of data on the baseline value of Ca19.9, the CT agents employed, the irradiated volume, and the radiation dose to nearby organs. However, the merit of this retrospective study lies in the identification of markers of benefit from CRT. 
Table 3. Recent studies comparing clinical outcomes of adjuvant chemoradiation therapy vs. other strategies in resected pancreatic cancer.

\begin{tabular}{|c|c|c|c|c|c|c|c|c|}
\hline Author & Year & $\begin{array}{c}\text { Clinical Study } \\
\text { Design }\end{array}$ & $\begin{array}{c}\mathrm{N} \text { of } \\
\text { Patients }\end{array}$ & Study Groups & RT Dose & RT Technique & Drugs & Key Results \\
\hline Morganti et al. [40] & 2014 & retrospective & 955 & $\begin{array}{l}\text { 3: RT, CT, or } \\
\text { CRT }\end{array}$ & 45-60 Gy & na & fluoropyrimidines & $\begin{array}{c}\text { OS: CRT } 39.9 \mathrm{mts} \\
\text { CT } 27.8 \mathrm{mts} \\
\text { RT } 24.8 \mathrm{mts}(p>0.001)\end{array}$ \\
\hline Parikh et al. [41] & 2015 & retrospective & 1130 & $\begin{array}{l}\text { 3: surgery, } \mathrm{CT} \text {, } \\
\text { CRT }\end{array}$ & 50 Gy & na & gemcitabine & $\begin{array}{c}\text { OS: } \\
\text { CT vs. surgery } \\
\text { HR 0.71 (0.57-0.89) } \\
\text { CRT vs. surgery } \\
\text { HR 0.84 (0.69-1.02) }\end{array}$ \\
\hline Rutter et al. [39] & 2015 & retrospective & 6165 & 2: CT or CRT & $50 \mathrm{~Gy}$ & na & na & $\begin{array}{c}\text { CRT vs. CT } \\
\text { OS: } 23.3 \text { vs. } 20 \mathrm{mts} \\
\text { 5-y OS: } 19.6 \% \text { vs. } 16.5 \%(p 0.001)\end{array}$ \\
\hline Osipov et al. [42] & 2017 & retrospective & 102 & 2: CT or CRT & na & na & na & $\begin{array}{c}>2 \mathrm{~mm} \text { resection margin vs. }<2 \mathrm{~mm}: \\
\text { Local RFS: HR } 0.20(0.05-0.88) \text { OS: HR } \\
0.31(0.14-0.74)\end{array}$ \\
\hline Kanji et al. [43] & 2018 & retrospective & 102 & 2: CT or CT-CRT & $50 \mathrm{~Gy}$ & na & $\begin{array}{l}\text { gemcitabine and } \\
\text { taxanes, then } \\
\text { fluoropyrimidines }\end{array}$ & $\begin{array}{c}\text { CCRT vs. CT } \\
\text { OS: HR } 0.08(p<0.001) \\
\text { DFS: HR } 0.23(p 0.001)\end{array}$ \\
\hline Hsieh et al. [44] & 2018 & prospective & 588 & $\begin{array}{c}\text { 3: CCRT, CRT, } \\
\text { CT }\end{array}$ & $50 \mathrm{~Gy}$ & IMRT & gemcitabine & $\begin{array}{c}\text { OS: } \\
\text { CCRT vs. CT } \\
\text { HR } 0.40(0.31-0.50) \\
\text { CRT vs. CT HR } 0.31(0.24-0.40) \\
\text { CRT vs. CCRT }(p 0.014)\end{array}$ \\
\hline Xu et al. [45] & 2018 & retrospective & 804 & $\begin{array}{c}\text { 3: surgery alone, } \\
\text { CT, CRT }\end{array}$ & $50 \mathrm{~Gy}$ & IMRT & gemcitabine & $\begin{array}{c}\text { CRT vs. no CRT: } \\
\text { OS } 23.7 \text { vs. } 17.0 \mathrm{mts} \\
p<0.001 \\
\text { RFS } 12.2 \text { vs. } 8.5 \mathrm{mts} \\
p<0.001\end{array}$ \\
\hline Ma et al. [46] & 2019 & retrospective & 5667 & $\begin{array}{c}\text { 3: CCRT, CRT, } \\
\text { CT }\end{array}$ & $>45 \mathrm{~Gy}$ & na & $\begin{array}{c}\text { 5FU or } \\
\text { gemcitabine }\end{array}$ & $\begin{array}{c}\text { OS: } \\
\text { CCRT vs. CT } 23.3 \text { vs. } 20.0 \\
\text { CCRT vs. CRT 23.4 vs. } 20.8(p>0.001)\end{array}$ \\
\hline
\end{tabular}

Abbreviations: 5FU = 5-fluorouracil; CT = chemotherapy; CCRT = chemotherapy followed by concurrent chemoradiation therapy $(\mathrm{CRT})$; DFS = disease-free survival; $\mathrm{mts}=$ months;

OS = overall survival; na =, not available; RFS = relapse-free survival; RT = radiation therapy; IMRT = intensity-modulated radiation therapy. 
More recently, the US National Cancer Database was subject to a second analysis [46], aimed to compare the clinical outcomes of CT followed by CRT vs. either CRT and then CT alone, in the specific population with stage I-II resected PDAC. RT dose should have been of at least $45 \mathrm{~Gy}$. The combined strategy (CT followed by CRT) achieved significantly longer OS than CT alone (median gap 3.3 months) and CRT alone (median gap 2.6 months). Again, the observed advantage from the combined strategy over CT or CRT was driven by N1 disease (HR 0.75), with no apparent effect in N0 resected tumors.

\section{Adjuvant Treatment: Metanalyses}

The reliability and applicability of data concerning adjuvant therapy in PDAC is often negatively affected by inter-study heterogeneity, regarding study population, stratification for prognostic contributors, and treatment options (surgery, CT regimens, RT dose, and techniques). Insufficient sample size is a frequent limitation among the published studies. A direct comparison between different adjuvant strategies lacking, metanalytic efforts tried to overcome these limitations and clarify the sometimes-unequivocal results emerging from randomized trials.

The first assessment of the role of adjuvant CT and RT [47] collected data from five randomized trials $[9,10,26,29,31]$, of which the ESPAC-1, including the outcomes of 261 pts outside the factorial design (ESPAC-1 plus), provided the bulk of the sample (550 pts, or $63 \%$ of the total). After exclusion of cases diagnosed as periampullary cancer, data from 875 pts were analyzed at a patient level, except those coming from the old GITSG trial.

OS reached 19 months with adjuvant CT (CI95\%, 16.4-21.1) vs. 13.5 months (CI95\%, 12.2-15.8) with surgery alone, with significant, moderate HRs ranging from 0.65 to 0.75 depending on the selected trials; 2 -y and 5-y OS were $38 \%$ and $19 \%$ for pts who received CT, and $28 \%$ and $12 \%$ for those who did not, respectively. To define the benefit from adjuvant CRT, data from ESPAC -1 ( $2 \times 2$ and Plus) and EORTC trials were pooled resulting in marginal heterogeneity $(p 0.05)$. CRT did not confer any OS advantage (HR 1.09, $p$ 0.43), with similar median values (15.8 months vs. 15.2 without CRT) and 5-y rates $(12 \%$ and $17 \%$, respectively). Even the inclusion of GITSG pts, characterized by a higher rate of R1 resections, only resulted in increased heterogeneity ( $p 0.02)$ with still no observed beneficial effect of CRT (HR 1.02, $p$ 0.81). In the subgroup analysis, a non-statistically significant trend for higher OS with CRT vs. CT was observed for G3 tumors and for R1 resections.

The effect of adjuvant 5FU-based CT or CRT was investigated with the aim of establishing the absolute size of the OS benefit [48]. Five randomized or non-randomized prospective trials (totaling 670 pts) were included in the analysis: GITSG, EORTC, ESPAC1 2×2, the Norwegian Pancreatic Cancer Trial (NPCT) [29] and the non-randomized USA experience reported by Yeo et al. [49]. Other series, containing metastatic pts, were excluded. A statistically significant difference in 2-year OS between pts who received adjuvant therapy and pts who received surgery alone had not been achieved in any of the included studies. In the metanalysis, no significant inter-study heterogeneity was detected ( $p 0.459)$, and adjuvant therapy was associated with a significant gain in 2-y OS of $12 \%(p 0.011)$, a beneficial effect that was independent of the addition of RT in the adjuvant setting.

Another metanalysis [50] included data from the CONKO-001 [13] and the trial by Kosuge et al. [28], besides the published results of ESPAC-1 and the trials by Bakkevold et al. [9], and Takada et al. [26]. A statistically significant 3-month long OS prolongation (C195\%, 0.3-5.7, $p 0.03$ ) was associate with adjuvant $\mathrm{CT}$ but the gain in 5-y OS was marginal and not significant (3.1\%, p ns). A statistically significant 3-month long OS prolongation (CI95\%, 0.3-5.7, $p$ 0.03) was associated with adjuvant CT but the gain in 5-y OS was marginal and not significant (3.1\%, p ns).

The impact of type of radical resection on treatment efficacy was analyzed on four trials ( $n=875$ ) [51]: $68 \%$ of the sample had experienced a R0 resection, whereas $32 \%$ a R1; R1 resection was positively associated with nodal involvement ( $63 \%$ vs. $49 \%$ in the R0 group). Interestingly, resection margin involvement did not prove a significant prognosticator (HR 1.10, $p 0.24$ ); however, the beneficial effect of adjuvant CT on OS resulted greater in R0-resected pts (OS 20.8 months vs. 13.8 in pts treated with surgery alone), as compared to R1 resections (OS 15 months vs. 13.2). In contrast, CRT ( $n=241)$ 
seemed to provide only a slight trend towards an OS advantage in R1-resected pts, emerging as a positive difference in median values of 3.5 months, as well as non-significant HR of 0.72 and 2-y and 5 -y rates (30\% vs. $19 \%$ with observation, and $18 \%$ vs. $8 \%$, respectively). A trend towards a detriment on OS was observed in R0-resected pts (HR 1.19, CI95\%, 0.95-1.49).

$\mathrm{Xu}$ et al. investigated the benefits of adjuvant CRT and neoadjuvant CRT in resectable pancreatic cancer. Seven studies were included in the comparison between CRT versus non-CRT and three studies were included in the comparison between neoadjuvant CRT versus post-operative CRT. In this meta-analysis CRT showed no significant effect on OS and PFS when compared to non-CRT, while neoadjuvant CRT showed no significant effect over post-operative adjuvant CRT [52].

A network metanalysis of nine trials [53] was able to perform a direct comparison among CT-only and combination strategies. The improvement in OS achieved by adjuvant CT with GEM or 5FU (HR 0.68 (CI95\% 0.44-1.07) and HR 0.62 (CI95\% 0.42-0.88), respectively) reached the full statistical significance after correction for nodal positivity, with conspicuous HRs of 0.59 and 0.65 , respectively. The addition of CRT to any adjuvant CT regimen did not improve the efficacy with possibly worse outcomes than CT alone; moreover, CRT caused a relevant rise of toxicities, more so in association with GEM CT than with 5FU CT.

More recently, another network metanalysis [54] evaluated nine different regimens described in 13 trials. S-1 and GEM-capecitabine appeared the most effective agents for adjuvant CT, and again adding CRT to CT was confirmed unable to exert any significant improvement in OS.

\section{Discussion}

Despite the efforts cast in the recent past, even for the resected disease, the prognosis of PDAC remains dismal, with long-term survival rates at the lower end of the spectrum of the gastrointestinal malignancies [55,56]. In the wake of the benefit observed in the ESPAC-4 trial [20], GEM-capecitabine has surged as a valid therapeutic option; however the methodologic caveats and the subgroup analysis of this trial suggest caution in considering the ESPAC-4 regimen as the sole standard regimen in the adjuvant setting.

While S-1 has shown the potential to enter the therapeutic armamentarium for Asian pts [21], the results from the JASPAC-01 trial may not be generalized to Western population. However, the 5-y OS of $18 \%-44 \%$ achieved by nucleoside analogues, either in monotherapy or in combination, are clearly insufficient and call for the incorporation of active agents endowed with different cytotoxic mechanisms. The rationale relies both on exploiting synergic effects between different classes of antineoplastic agents [57], and on maximizing the chances of eradication of all the microscopic residues of a disease characterized by marked inter-tumoral heterogeneity [58]. The main road currently walked towards intensification is represented by the transposition of regimens which demonstrated meaningful efficacy in the advanced setting [25,59]. Indeed, a modified version of FOLFIRINOX markedly improved survival [60], whereas less neat results were divulged at American Society of Clinical Oncology(ASCO) Annual Meeting and European Society for Medical Oncology (ESMO) Congress 2019 for the Adjuvant Therapy for Patients With Resected Pancreatic Cancer (APACT) study, a phase-3 trial that evaluated the addition of nab-paclitaxel to GEM [61]. It is noteworthy that the experimental arms of both trials were compared against GEM alone, not with the doublet with capecitabine. Moreover, another significant limitation is represented by toxicity: the experimental regimens were associated with G3-4 adverse events in a larger share of pts (76-86\%) than GEM monotherapy, even in selected populations that do not resemble the real-world typical patient who had undergone the invasive surgery required for PDAC radical removal. It is predictable that the mainstay of treatment of less-performing pts will not benefit from this kind of evidence and will remain based on GEM monotherapy or combined with capecitabine.

New evidence brought new issues, which add up to old, unresolved questions. Ongoing studies (Table 4) will hopefully provide an answer to part of them. 
Table 4. Pending results from randomized trials regarding either adjuvant or combined neoadjuvant and adjuvant treatments in resectable pancreatic cancer, as listed on www.clinicaltrials.gov, www.clinicaltrialsregister.eu and www.umin.ac.jp by September 2019.

\begin{tabular}{|c|c|c|c|c|c|}
\hline Identifiers & Phase & $\begin{array}{l}\text { Planned } \\
\text { Accrual }\end{array}$ & Interventions & Primary Endpoint & $\begin{array}{c}\text { Estimated Study } \\
\text { Completion Date-Status }\end{array}$ \\
\hline GIP-2 NCT02355119 & III & 310 & Gem vs. FOLFOXIRI & DFS & Dec, 2018-status unknown \\
\hline IMPRESS NCT01072981 & III & 722 & Gem \pm 5FU-based CRT vs. Gem \pm CRT + Alg & OS & $\begin{array}{l}\text { May, 2016-anticipated } \\
\text { negative results }\end{array}$ \\
\hline NCT02005419 & IIR & 300 & Gem vs. Gem + Met & 1-y RFS & Dec, 2017 \\
\hline NEPAFOX NCT02172976 & II/III & 40 & Perioperative FOLFIRINOX vs. adjuvant Gem & OS & Jul, 2019 \\
\hline RTOG 0848 NCT01013649 & II/III & 545 & $\begin{array}{c}\text { Combination CT/Gem vs. Erl + Gem, followed by } \\
\text { previous CT } \pm 5 \mathrm{FU} / \text { Cap-based CRT }\end{array}$ & OS & $\begin{array}{l}\text { Aug, 2020-partial } \\
\text { preliminary results }\end{array}$ \\
\hline HEAT NCT01077427 & III & 336 & Gem + Cis + regional hyperthermia vs. Gem + Cap & DFS & Mar, 2021 \\
\hline $\begin{array}{l}\text { SWOG S1505 } \\
\text { NCT02562716 }\end{array}$ & IIR & 112 & $\begin{array}{l}\text { Perioperative FOLFIRINOX vs. perioperative } \\
\text { nabP + Gem }\end{array}$ & OS & Oct, 2021 \\
\hline NCT02451982 & I/IIR & 75 & $\begin{array}{l}\text { Perioperative CTX + GVAX + Gem + RT vs. perioperative } \\
\text { CTX + GVAX + Niv } \pm \text { Ure + Gem + RT }\end{array}$ & $\begin{array}{l}\text { IL-17A expression in } \\
\text { resected tumors }\end{array}$ & Feb, 2023 \\
\hline NCT03959150 & II/III & 231 & Gem + Cap followed by metronomic Cap vs. Gem + Cap & 1-y DFS & Jun, 2023 \\
\hline NEONAX NCT02047513 & IIR & 166 & Perioperative nabP + Gem vs. adjuvant nabP + Gem & DFS & Sep, 2024 \\
\hline
\end{tabular}

Abbreviations: $5 \mathrm{FU}$ = fluorouracil; $\mathrm{Alg}=$ algenpantucel-L; Cap = capecitabine; Cis = cisplatin; CRT = chemoradiation therapy; CT = chemotherapy; CTX = cyclophosphamide;

$\mathrm{DFS}$ = disease-free survival; $\mathrm{Erl}=$ erlotinib; Gem = gemcitabine; $\mathrm{IL}=$ interleukin; Met = metformin; nab = nab-paclitaxel; Niv = nivolumab; OS = overall survival; RFS = relapse-free survival; RT = radiotherapy; SBRT = stereotactic body radiation therapy; Ure = urelumab; y = year; GIP-2: Gruppo Italiano Pancreas-2; RTOG: Radiation Therapy Oncology Group; HEAT: Hyperthermia European Adjuvant Trial; SWOG: Southwest Oncology Group; NEONAX: Neoadjuvant Plus Adjuvant or Only Adjuvant Nab-Paclitaxel Plus Gemcitabine for Resectable Pancreatic Cancer; FOLFOXIRI: Combination of 5-Fluorouracil/Folinic Acid, Oxaliplatin and Irinotecan GVAX: immune system activating pancreatic cancer vaccine. 
First, the identification of subgroups of pts in whom the efficacy of adjuvant CT is enhanced or diminished could be of help in the clinical practice. Unfortunately, easily retrievable prognostic factors, such as nodal involvement [62] and resection margins [63], failed to predict efficacy of adjuvant CT. With the caveats related to subgroup analysis (not pre-planned, reduced statistical power, $\mathrm{p}$ for interaction inconstantly reported), none of the five randomized clinical trials that reported one $[10,20,21,60,61]$ could demonstrate a clear-cut difference of effect between arms according to the partition into these two subgroups. Molecular biology or immunohistochemistry can provide biomarkers that cut across the inconclusive clinical-pathological groupings. However, research in this field is still very immature, as only a few unvalidated predictive biomarkers of chemoresistance to adjuvant $\mathrm{CT}$ have been hypothesized so far [64,65].

Second, a major improvement in postsurgical survival could be represented by the incorporation of RT into the adjuvant setting. Unfortunately, in contrast to the CT approach, trials in this field are particularly scant. The few historical randomized trials were conducted during a large timespan, suffer with methodological flaws, and employed heterogeneous treatments. In particular, the employed RT dose was later recognized as suboptimal. Unsurprisingly, conflicting results and difficulties in data interpretation, the role of adjuvant RT is still controversial, even among international scientific societies. ASCO guidelines [66] recommend with a moderate strength to add adjuvant CRT after four to six months of systemic adjuvant chemotherapy for patients with lymph node-positive or R1 disease. In contrast, considering that survival benefit from adding CRT to adjuvant gemcitabine has not been definitely shown by strong evidence, ESMO guidelines do not recommend adjuvant CRT outside clinical trials [67]. Importantly, the recently released American Society for Radiation Oncology (ASTRO) guidelines lukewarmly endorse adjuvant CRT, for select high-risk patients defined by positive lymph nodes and surgical margins [68].

Against the hitherto presented backdrop, several issues on adjuvant CRT in PDAC still need adequate clarification. The evolution of RT techniques led to more effective radiation treatments, such as stereotactic body RT and intensity-modulated RT (IMRT), allowing more conformal dose delivery, and whose improved efficacy still need to be put properly on the test. A step further, the application to the post-operative setting of innovative techniques that are being pursued in other settings of PDAC care (NCT03536182, NCT03822936) could open new room for research.

On the other hand, the continuous improvement of adjuvant CT regimens -which in recent years increased to a great extent the chances of long-term survival after surgical resection [20,60]-could overshadow beneficial effects from CRT observed with less effective CT regimens. As a case in point, the ongoing phase-3 RTOG 0848 trial (NCT01013649) will provide useful data on optimal adjuvant CRT, in which an adequate dose is delivered also through IMRT, and to standardized, evidence-based target volumes. However, the employed adjuvant CT is still GEM monotherapy, so that dedicated trials will still be needed to elucidate the utility of and the efficiency in improving local control under these new conditions.

Considering that not all resected patients will benefit from adjuvant CRT, which on the other hand is not free from toxicities, more accurate negative and positive predictors of clinical benefit from CRT is a felt clinical need [45], which could find an answer in molecular biology and genetics. An ideal biomarker, or combination of biomarkers, should be able to indicate with high accuracy both the persistence of local disease, and its radiosensitivity.

Another line of research should further explore the addition of agents able to sensitize tumor cells to CT and CRT damage for systemic and local control, respectively. This approach has been initially investigated in locally advanced, inoperable PDAC with encouraging results [69].

Lastly, RT has showed an important effect on the immunosuppressive tumor microenvironment, which could be exploited to overcome the notorious resistance to immunotherapy typical of PDAC. Multiple studies currently are investigating PDAC vaccines (immune system activating pancreatic cancer vaccine (GVAX), Algenpantucel-L), in combination with CT or CT + CRT after surgical resection (NCT02451982, NCT01072981). 
Third, a wider view of the treatment sequence will possibly improve the prognosis of primarily resectable PDAC. In particular, a few phase- 2 randomized trials are evaluating the anticipation of $\mathrm{CT}$ to the preoperative setting. This approach should be able to ensure treatment administration to a higher proportion of pts than post-operative $\mathrm{CT}$, the exclusion of early progressors from surgery, as well as decrease the rate of R1 resections. Interim results of the ongoing Neoadjuvant Plus Adjuvant or Only Adjuvant Nab-Paclitaxel Plus Gemcitabine for Resectable Pancreatic Cancer (NEONAX) trial (ASCO Annual Meeting 2019, abstract 4128 [70]) suggest the safety of the preoperative approach with GEM-nabpaclitaxel, whereas the combination of 5-Fluorouracil/Folinic Acid and Oxaliplatin (FOLFOX) and mFOLFIRINOX regimens are being evaluated in the PANACHE01-PRODIGE48 trial (NCT02959879). Indeed, preliminary efficacy outcomes from the phase-3 Prep-02/ Japanese Study Group of Adjuvant Therapy for Pancreatic Cancer (JSAP)-05 trial [71] favor the neoadjuvant approach with GEM-S-1 over upfront surgery in Asian pts, observing a 10-month, statistically significant difference in median OS.

\section{Conclusions}

After decades of slow progress, considerable advances have been recently made in the development of adjuvant strategies and protocols for resected PDAC, resulting in an unprecedentedly dynamic scenario, and sparkling new hope for the cure of this highly lethal, recalcitrant disease. However, at present survival rates remain unacceptably low, and dedicated research efforts are still urgently needed to improve the prognosis of these patients.

Funding: Funding was provided by the project Progetto di Rete-NET2011-02352137 “Genomic base triage for target therapy in colorectal cancer-Ricerca Sanitaria Finalizzata 2011" from the Italian Ministry of Health. This work was also supported by grants from the Fondazione del Piemonte per l'Oncologia (Istituto di Ricovero e Cura a Carattere Scientifico Candiolo) and the Fondazione Piemontese per la Ricerca sul Cancro 5 x mille Ministero della Salute.

Conflicts of Interest: The authors declare no conflict of interest. The funders had no role in the design of the study; in the collection, analyses, or interpretation of data; in the writing of the manuscript, or in the decision to publish the results.

\section{References}

1. Ryan, D.P.; Hong, T.S.; Bardeesy, N. Pancreatic adenocarcinoma. N. Engl. J. Med. 2014, 371, 1039-1049. [CrossRef] [PubMed]

2. Siegel, R.L.; Miller, K.D.; Jemal, A. Cancer statistics, 2018. CA Cancer J. Clin. 2018, 68, 7-30. [CrossRef] [PubMed]

3. Neoptolemos, J.P.; Kleeff, J.; Michl, P.; Costello, E.; Greenhalf, W.; Palmer, D.H. Therapeutic developments in pancreatic cancer: Current and future perspectives. Nat. Rev. Gastroenterol. Hepatol. 2018, 15, 333-348. [CrossRef] [PubMed]

4. Le, D.T.; Durham, J.N.; Smith, K.N.; Wang, H.; Bartlett, B.R.; Aulakh, L.K.; Lu, S.; Kemberling, H.; Wilt, C.; Luber, B.S.; et al. Mismatch repair deficiency predicts response of solid tumors to PD-1 blockade. Science 2017, 357, 409-413. [CrossRef]

5. Chiorean, E.G.; Coveler, A.L. Pancreatic cancer: Optimizing treatment options, new, and emerging targeted therapies. Drug Des. Devel. Ther. 2015, 9, 3529-3545. [CrossRef]

6. Heinemann, V.; Boeck, S. Perioperative management of pancreatic cancer. Ann. Oncol. 2008, 19, 273-278. [CrossRef]

7. Oberstein, P.E.; Olive, K.P. Pancreatic cancer: Why is it so hard to treat? Therap. Adv. Gastroenterol. 2013, 6, 321-337. [CrossRef]

8. Shibata, K.; Matsumoto, T.; Yada, K.; Sasaki, A.; Ohta, M.; Kitano, S. Factors predicting recurrence after resection of pancreatic ductal carcinoma. Pancreas 2005, 31, 69-73. [CrossRef]

9. Bakkevold, K.E.; Arnesjø, B.; Dahl, O.; Kambestad, B. Adjuvant combination chemotherapy (AMF) following radical resection of carcinoma of the pancreas and papilla of Vater-results of a controlled, prospective, randomised multicentre study. Eur. J. Cancer 1993, 29, 698-703. [CrossRef] 
10. Neoptolemos, J.P.; Stocken, D.D.; Friess, H.; Bassi, C.; Dunn, J.A.; Hickey, H.; Beger, H.; Fernandez-Cruz, L.; Dervenis, C.; Lacaine, F.; et al. A randomized trial of chemoradiotherapy and chemotherapy after resection of pancreatic cancer. N. Engl. J. Med. 2004, 350, 1200-1210. [CrossRef]

11. Neoptolemos, J.P.; Stocken, D.D.; Tudur Smith, C.; Bassi, C.; Ghaneh, P.; Owen, E.; Moore, M.; Padbury, R.; Doi, R.; Smith, D.; et al. Adjuvant 5-fluorouracil and folinic acid vs. observation for pancreatic cancer: Composite data from the ESPAC-1 and -3(v1) trials. Br. J. Cancer 2009, 100, 246-250. [CrossRef] [PubMed]

12. Oettle, H.; Post, S.; Neuhaus, P.; Gellert, K.; Langrehr, J.; Ridwelski, K.; Schramm, H.; Fahlke, J.; Zuelke, C.; Burkart, C.; et al. Adjuvant chemotherapy with gemcitabine vs. observation in patients undergoing curative-intent resection of pancreatic cancer: A randomized controlled trial. Jama 2007, 297, 267-277. [CrossRef] [PubMed]

13. Oettle, H.; Neuhaus, P.; Hochhaus, A.; Hartmann, J.T.; Gellert, K.; Ridwelski, K.; Niedergethmann, M.; Zülke, C.; Fahlke, J.; Arning, M.B.; et al. Adjuvant chemotherapy with gemcitabine and long-term outcomes among patients with resected pancreatic cancer: The CONKO-001 randomized trial. Jama 2013, 310, 1473-1481. [CrossRef] [PubMed]

14. Ueno, H.; Kosuge, T.; Matsuyama, Y.; Yamamoto, J.; Nakao, A.; Egawa, S.; Doi, R.; Monden, M.; Hatori, T.; Tanaka, M.; et al. A randomised phase III trial comparing gemcitabine with surgery-only in patients with resected pancreatic cancer: Japanese study group of adjuvant therapy for pancreatic cancer. Br. J. Cancer 2009, 101, 908-915. [CrossRef]

15. Neoptolemos, J.P.; Stocken, D.D.; Bassi, C.; Ghaneh, P.; Cunningham, D.; Goldstein, D.; Padbury, R.; Moore, M.J.; Gallinger, S.; Mariette, C.; et al. Adjuvant chemotherapy with fluorouracil plus folinic acid vs. gemcitabine following pancreatic cancer resection: A randomized controlled trial. Jama 2010, 304, 1073-1081. [CrossRef]

16. Herrmann, R.; Bodoky, G.; Ruhstaller, T.; Glimelius, B.; Bajetta, E.; Schüller, J.; Saletti, P.; Bauer, J.; Figer, A.; Pestalozzi, B.; et al. Gemcitabine plus capecitabine compared with gemcitabine alone in advanced pancreatic cancer: A randomized, multicenter, phase III trial of the swiss group for clinical cancer research and the central european cooperative oncology group. J. Clin. Oncol. 2007, 25, 2212-2217. [CrossRef]

17. Cunningham, D.; Chau, I.; Stocken, D.D.; Valle, J.W.; Smith, D.; Steward, W.; Harper, P.G.; Dunn, J.; Tudur-Smith, C.; West, J.; et al. Phase III randomized comparison of gemcitabine versus gemcitabine plus capecitabine in patients with advanced pancreatic cancer. J. Clin. Oncol. 2009, 27, 5513-5518. [CrossRef]

18. Lee,H.S.; Chung, M.J.; Park, J.Y.; Bang, S.; Park, S.W.; Kim,H.G.; Noh, M.H.; Lee, S.H.; Kim, Y.T.; Kim, H.J.; et al. A randomized, multicenter, phase III study of gemcitabine combined with capecitabine versus gemcitabine alone as first-line chemotherapy for advanced pancreatic cancer in South Korea. Medicine (Baltimore) 2017, 96, e5702. [CrossRef]

19. Jones, R.P.; Psarelli, E.E.; Jackson, R.; Ghaneh, P.; Halloran, C.M.; Palmer, D.H.; Campbell, F.; Valle, J.W.; Faluyi, O.; O'Reilly, D.A.; et al. Patterns of recurrence after resection of pancreatic ductal adenocarcinoma: A secondary analysis of the ESPAC-4 randomized adjuvant chemotherapy trial. JAMA Surg. 2019. [CrossRef]

20. Neoptolemos, J.P.; Palmer, D.H.; Ghaneh, P.; Psarelli, E.E.; Valle, J.W.; Halloran, C.M.; Faluyi, O.; O’Reilly, D.A.; Cunningham, D.; Wadsley, J.; et al. Comparison of adjuvant gemcitabine and capecitabine with gemcitabine monotherapy in patients with resected pancreatic cancer (ESPAC-4): A multicentre, open-label, randomised, phase 3 trial. Lancet 2017, 389, 1011-1024. [CrossRef]

21. Uesaka, K.; Boku, N.; Fukutomi, A.; Okamura, Y.; Konishi, M.; Matsumoto, I.; Kaneoka, Y.; Shimizu, Y.; Nakamori, S.; Sakamoto, H.; et al. Adjuvant chemotherapy of S-1 versus gemcitabine for resected pancreatic cancer: A phase 3, open-label, randomised, non-inferiority trial (JASPAC 01). Lancet 2016, 388, $248-257$. [CrossRef]

22. Moore, M.J.; Goldstein, D.; Hamm, J.; Figer, A.; Hecht, J.R.; Gallinger, S.; Au, H.J.; Murawa, P.; Walde, D.; Wolff, R.A.; et al. Erlotinib plus gemcitabine compared with gemcitabine alone in patients with advanced pancreatic cancer: A phase III trial of the national cancer institute of canada clinical trials group. J. Clin. Oncol. 2007, 25, 1960-1966. [CrossRef] [PubMed]

23. Sinn, M.; Bahra, M.; Liersch, T.; Gellert, K.; Messmann, H.; Bechstein, W.; Waldschmidt, D.; Jacobasch, L.; Wilhelm, M.; Rau, B.M.; et al. CONKO-005: Adjuvant chemotherapy with gemcitabine plus erlotinib versus gemcitabine alone in patients after R0 resection of pancreatic cancer: A multicenter randomized phase III trial. J. Clin. Oncol. 2017, 35, 3330-3337. [CrossRef] [PubMed] 
24. Sinn, M.; Liersch, T.; Gellert, K.; Riess, H.; Stübs, P.; Waldschmidt, D.T.; Pelzer, U.; Stieler, J.; Striefler, J.K.; Bahra, M.B. LBA18CONKO-006: A randomized double-blinded phase IIB-study of adjuvant therapy with gemcitabine + sorafenib/placebo for patients with R1-resection of pancreatic cancer. Ann. Oncol. 2014. [CrossRef]

25. Conroy, T.; Desseigne, F.; Ychou, M.; Bouché, O.; Guimbaud, R.; Bécouarn, Y.; Adenis, A.; Raoul, J.L.; Gourgou-Bourgade, S.; de la Fouchardière, C.; et al. FOLFIRINOX versus gemcitabine for metastatic pancreatic cancer. N. Engl. J. Med. 2011, 364, 1817-1825. [CrossRef]

26. Takada, T.; Amano, H.; Yasuda, H.; Nimura, Y.; Matsushiro, T.; Kato, H.; Nagakawa, T.; Nakayama, T. Is postoperative adjuvant chemotherapy useful for gallbladder carcinoma? Cancer 2002, 95, 1685-1695. [CrossRef]

27. Neoptolemos, J.P.; Stocken, D.D.; Dunn, J.A.; Almond, J.; Beger, H.G.; Pederzoli, P.; Bassi, C.; Dervenis, C.; Fernandez-Cruz, L.; Lacaine, F.; et al. Influence of resection margins on survival for patients with pancreatic cancer treated by adjuvant chemoradiation and/or chemotherapy in the ESPAC-1 randomized controlled trial. Ann. Surg. 2001, 234, 758-768. [CrossRef]

28. Kosuge, T.; Kiuchi, T.; Mukai, K.; Kakizoe, T. A multicenter randomized controlled trial to evaluate the effect of adjuvant cisplatin and 5-fluorouracil therapy after curative resection in cases of pancreatic cancer. Jpn. J. Clin. Oncol. 2006, 36, 159-165. [CrossRef]

29. Kalser, M.H.; Ellenberg, S.S. Pancreatic cancer. Adjuvant combined radiation and chemotherapy following curative resection. Arch. Surg. 1985, 120, 899-903. [CrossRef]

30. Morak, M.J.; van der Gaast, A.; Incrocci, L.; van Dekken, H.; Hermans, J.J.; Jeekel, J.; Hop, W.C.; Kazemier, G.; van Eijck, C.H. Adjuvant intra-arterial chemotherapy and radiotherapy versus surgery alone in resectable pancreatic and periampullary cancer: A prospective randomized controlled trial. Ann. Surg. 2008, 248, 1031-1041. [CrossRef]

31. Klinkenbijl, J.H.; Jeekel, J.; Sahmoud, T.; van Pel, R.; Couvreur, M.L.; Veenhof, C.H.; Arnaud, J.P.; Gonzalez, D.G.; de Wit, L.T.; Hennipman, A.; et al. Adjuvant radiotherapy and 5-fluorouracil after curative resection of cancer of the pancreas and periampullary region: Phase III trial of the EORTC gastrointestinal tract cancer cooperative group. Ann. Surg. 1999, 230, 776-782. [CrossRef] [PubMed]

32. Smeenk, H.G.; van Eijck, C.H.; Hop, W.C.; Erdmann, J.; Tran, K.C.; Debois, M.; van Cutsem, E.; van Dekken, H.; Klinkenbijl, J.H.; Jeekel, J. Long-term survival and metastatic pattern of pancreatic and periampullary cancer after adjuvant chemoradiation or observation: Long-term results of EORTC trial 40891. Ann. Surg. 2007, 246, 734-740. [CrossRef] [PubMed]

33. Regine, W.F.; Winter, K.A.; Abrams, R.A.; Safran, H.; Hoffman, J.P.; Konski, A.; Benson, A.B.; Macdonald, J.S.; Kudrimoti, M.R.; Fromm, M.L.; et al. Fluorouracil vs. gemcitabine chemotherapy before and after fluorouracil-based chemoradiation following resection of pancreatic adenocarcinoma: A randomized controlled trial. Jama 2008, 299, 1019-1026. [CrossRef] [PubMed]

34. Regine, W.F.; Winter, K.A.; Abrams, R.; Safran, H.; Hoffman, J.P.; Konski, A.; Benson, A.B.; Macdonald, J.S.; Rich, T.A.; Willett, C.G. Fluorouracil-based chemoradiation with either gemcitabine or fluorouracil chemotherapy after resection of pancreatic adenocarcinoma: 5-year analysis of the U.S. Intergroup/RTOG 9704 phase III trial. Ann. Surg. Oncol. 2011, 18, 1319-1326. [CrossRef] [PubMed]

35. Abrams, R.A.; Winter, K.A.; Regine, W.F.; Safran, H.; Hoffman, J.P.; Lustig, R.; Konski, A.A.; Benson, A.B.; Macdonald, J.S.; Rich, T.A.; et al. Failure to adhere to protocol specified radiation therapy guidelines was associated with decreased survival in RTOG 9704-a phase III trial of adjuvant chemotherapy and chemoradiotherapy for patients with resected adenocarcinoma of the pancreas. Int. J. Radiat. Oncol. Biol. Phys. 2012, 82, 809-816. [CrossRef] [PubMed]

36. Van Laethem, J.L.; Hammel, P.; Mornex, F.; Azria, D.; Van Tienhoven, G.; Vergauwe, P.; Peeters, M.; Polus, M.; Praet, M.; Mauer, M.; et al. Adjuvant gemcitabine alone versus gemcitabine-based chemoradiotherapy after curative resection for pancreatic cancer: A randomized EORTC-40013-22012/FFCD-9203/GERCOR phase II study. J. Clin. Oncol. 2010, 28, 4450-4456. [CrossRef] [PubMed]

37. Moghanaki, D. Further evidence of effective adjuvant combined radiation and chemotherapy following curative resection of pancreatic cancer. gastrointestinal tumor study group. Cancer 1987, 59, 2006-2010. [CrossRef] 
38. Schmidt, J.; Abel, U.; Debus, J.; Harig, S.; Hoffmann, K.; Herrmann, T.; Bartsch, D.; Klein, J.; Mansmann, U.; Jäger, D.; et al. Open-label, multicenter, randomized phase III trial of adjuvant chemoradiation plus interferon Alfa-2b versus fluorouracil and folinic acid for patients with resected pancreatic adenocarcinoma. J. Clin. Oncol. 2012, 30, 4077-4083. [CrossRef]

39. Rutter, C.E.; Park, H.S.; Corso, C.D.; Lester-Coll, N.H.; Mancini, B.R.; Yeboa, D.N.; Johung, K.L. Addition of radiotherapy to adjuvant chemotherapy is associated with improved overall survival in resected pancreatic adenocarcinoma: An analysis of the National Cancer Data Base. Cancer 2015, 121, 4141-4149. [CrossRef]

40. Morganti, A.G.; Falconi, M.; van Stiphout, R.G.; Mattiucci, G.C.; Alfieri, S.; Calvo, F.A.; Dubois, J.B.; Fastner, G.; Herman, J.M.; Maidment, B.W.; et al. Multi-institutional pooled analysis on adjuvant chemoradiation in pancreatic cancer. Int. J. Radiat. Oncol. Biol. Phys. 2014, 90, 911-917. [CrossRef]

41. Parikh, A.A.; Maiga, A.; Bentrem, D.; Squires, M.H.; Kooby, D.A.; Maithel, S.K.; Weber, S.M.; Cho, C.S.; Katz, M.; Martin, R.C.; et al. Adjuvant therapy in pancreas cancer: Does it influence patterns of recurrence? J. Am. Coll. Surg. 2016, 222, 448-456. [CrossRef] [PubMed]

42. Osipov, A.; Nissen, N.; Rutgers, J.; Dhall, D.; Naziri, J.; Chopra, S.; Li, Q.; Hendifar, A.E.; Tuli, R. Redefining the positive margin in pancreatic cancer: Impact on patterns of failure, long-term survival and adjuvant therapy. Ann. Surg. Oncol. 2017, 24, 3674-3682. [CrossRef] [PubMed]

43. Kanji, Z.S.; Edwards, A.M.; Mandelson, M.T.; Sahar, N.; Lin, B.S.; Badiozamani, K.; Song, G.; Alseidi, A.; Biehl, T.R.; Kozarek, R.A.; et al. Gemcitabine and taxane adjuvant therapy with chemoradiation in resected pancreatic cancer: A novel strategy for improved survival? Ann. Surg. Oncol. 2018, 25, 1052-1060. [CrossRef]

44. Hsieh, M.C.; Chang, W.W.; Yu, H.H.; Lu, C.Y.; Chang, C.L.; Chow, J.M.; Chen, S.U.; Cheng, Y.; Wu, S.Y. Adjuvant radiotherapy and chemotherapy improve survival in patients with pancreatic adenocarcinoma receiving surgery: Adjuvant chemotherapy alone is insufficient in the era of intensity modulation radiation therapy. Cancer Med. 2018, 7, 2328-2338. [CrossRef] [PubMed]

45. Xu, H.X.; Li, S.; Wu, C.T.; Qi, Z.H.; Wang, W.Q.; Jin, W.; Gao, H.L.; Zhang, S.R.; Xu, J.Z.; Liu, C.; et al. Postoperative serum CA19-9, CEA and CA125 predicts the response to adjuvant chemoradiotherapy following radical resection in pancreatic adenocarcinoma. Pancreatology 2018, 18, 671-677. [CrossRef] [PubMed]

46. Ma, S.J.; Hermann, G.M.; Prezzano, K.M.; Serra, L.M.; Iovoli, A.J.; Singh, A.K. Adjuvant chemotherapy followed by concurrent chemoradiation is associated with improved survival for resected stage I-II pancreatic cancer. Cancer Med. 2019, 8, 939-952. [CrossRef]

47. Stocken, D.D.; Büchler, M.W.; Dervenis, C.; Bassi, C.; Jeekel, H.; Klinkenbijl, J.H.; Bakkevold, K.E.; Takada, T.; Amano, H.; Neoptolemos, J.P.; et al. Meta-analysis of randomised adjuvant therapy trials for pancreatic cancer. Br. J. Cancer 2005, 92, 1372-1381. [CrossRef]

48. Khanna, A.; Walker, G.R.; Livingstone, A.S.; Arheart, K.L.; Rocha-Lima, C.; Koniaris, L.G. Is adjuvant 5-FU-based chemoradiotherapy for resectable pancreatic adenocarcinoma beneficial? A meta-analysis of an unanswered question. J. Gastrointest. Surg. 2006, 10, 689-697. [CrossRef]

49. Yeo, C.J.; Abrams, R.A.; Grochow, L.B.; Sohn, T.A.; Ord, S.E.; Hruban, R.H.; Zahurak, M.L.; Dooley, W.C.; Coleman, J.; Sauter, P.K.; et al. Pancreaticoduodenectomy for pancreatic adenocarcinoma: Postoperative adjuvant chemoradiation improves survival. A prospective, single-institution experience. Ann. Surg. 1997, 225, 621-633. [CrossRef]

50. Boeck, S.; Ankerst, D.P.; Heinemann, V. The role of adjuvant chemotherapy for patients with resected pancreatic cancer: Systematic review of randomized controlled trials and meta-analysis. Oncology 2007, 72, 314-321. [CrossRef]

51. Butturini, G.; Stocken, D.D.; Wente, M.N.; Jeekel, H.; Klinkenbijl, J.H.; Bakkevold, K.E.; Takada, T.; Amano, H.; Dervenis, C.; Bassi, C.; et al. Influence of resection margins and treatment on survival in patients with pancreatic cancer: Meta-analysis of randomized controlled trials. Arch. Surg. 2008, 143, 75-83. [CrossRef] [PubMed]

52. Xu, C.P.; Xue, X.J.; Liang, N.; Xu, D.G.; Liu, F.J.; Yu, X.S.; Zhang, J.D. Effect of chemoradiotherapy and neoadjuvant chemoradiotherapy in resectable pancreatic cancer: A systematic review and meta-analysis. J. Cancer Res. Clin. Oncol. 2014, 140, 549-559. [CrossRef] [PubMed]

53. Liao, W.C.; Chien, K.L.; Lin, Y.L.; Wu, M.S.; Lin, J.T.; Wang, H.P.; Tu, Y.K. Adjuvant treatments for resected pancreatic adenocarcinoma: A systematic review and network meta-analysis. Lancet. Oncol. 2013, 14, 1095-1103. [CrossRef] 
54. Xu, J.B.; Jiang, B.; Chen, Y.; Qi, F.Z.; Zhang, J.H.; Yuan, H. Optimal adjuvant chemotherapy for resected pancreatic adenocarcinoma: A systematic review and network meta-analysis. Oncotarget 2017, 8, 81419-81429. [CrossRef] [PubMed]

55. Grothey, A.; Sobrero, A.F.; Shields, A.F.; Yoshino, T.; Paul, J.; Taieb, J.; Souglakos, J.; Shi, Q.; Kerr, R.; Labianca, R.; et al. Duration of adjuvant chemotherapy for stage III colon cancer. N. Engl. J. Med. 2018, 378, 1177-1188. [CrossRef] [PubMed]

56. Al-Batran, S.E.; Homann, N.; Pauligk, C.; Goetze, T.O.; Meiler, J.; Kasper, S.; Kopp, H.G.; Mayer, F.; Haag, G.M.; Luley, K.; et al. Perioperative chemotherapy with fluorouracil plus leucovorin, oxaliplatin, and docetaxel versus fluorouracil or capecitabine plus cisplatin and epirubicin for locally advanced, resectable gastric or gastro-oesophageal junction adenocarcinoma (FLOT4): A randomised, phase 2/3 trial. Lancet 2019, 393, 1948-1957. [CrossRef] [PubMed]

57. Frese, K.K.; Neesse, A.; Cook, N.; Bapiro, T.E.; Lolkema, M.P.; Jodrell, D.I.; Tuveson, D.A. Nab-paclitaxel potentiates gemcitabine activity by reducing cytidine deaminase levels in a mouse model of pancreatic cancer. Cancer Discov. 2012, 2, 260-269. [CrossRef]

58. Raphael, B.J.; Hruban, R.H.; Aguirre, A.J.; Moffitt, R.A.; Yeh, J.J.; Stewart, C.; Robertson, A.G.; Cherniack, A.D.; Gupta, M.; Getz, M.; et al. Integrated Genomic characterization of pancreatic ductal adenocarcinoma. Cancer Cell 2017, 32, 185-203. [CrossRef]

59. Von Hoff, D.D.; Ervin, T.; Arena, F.P.; Chiorean, E.G.; Infante, J.; Moore, M.; Seay, T.; Tjulandin, S.A.; Ma, W.W.; Saleh, M.N.; et al. Increased survival in pancreatic cancer with nab-paclitaxel plus gemcitabine. N. Engl. J. Med. 2013, 369, 1691-1703. [CrossRef]

60. Conroy, T.; Hammel, P.; Hebbar, M.; Ben Abdelghani, M.; Wei, A.C.; Raoul, J.L.; Choné, L.; Francois, E.; Artru, P.; Biagi, J.J.; et al. FOLFIRINOX or gemcitabine as adjuvant therapy for pancreatic cancer. N. Engl. J. Med. 2018, 379, 2395-2406. [CrossRef]

61. Tempero, M.A.; Reni, M.; Riess, H.; Pelzer, U.; O’Reilly, E.M.; Winter, J.M.; Oh, D.-Y.; Li, C.-P.; Tortora, G.; Chang, H.-M. APACT: Phase III, multicenter, international, open-label, randomized trial of adjuvant nab-paclitaxel plus gemcitabine (nab-P/G) vs. gemcitabine $(\mathrm{G})$ for surgically resected pancreatic adenocarcinoma. J. Clin. Oncol. 2019, 37 (Suppl. 15), 4000. [CrossRef]

62. Morales-Oyarvide, V.; Rubinson, D.A.; Dunne, R.F.; Kozak, M.M.; Bui, J.L.; Yuan, C.; Qian, Z.R.; Babic, A.; Da Silva, A.; Nowak, J.A.; et al. Lymph node metastases in resected pancreatic ductal adenocarcinoma: Predictors of disease recurrence and survival. Br. J. Cancer 2017, 117, 1874-1882. [CrossRef] [PubMed]

63. Tummala, P.; Howard, T.; Agarwal, B. Dramatic survival benefit related to R0 resection of pancreatic adenocarcinoma in patients with tumor $\leq 25 \mathrm{~mm}$ in size and $\leq 1$ involved lymph nodes. Clin. Transl. Gastroenterol. 2013, 4, e33. [CrossRef] [PubMed]

64. Greenhalf, W.; Ghaneh, P.; Neoptolemos, J.P.; Palmer, D.H.; Cox, T.F.; Lamb, R.F.; Garner, E.; Campbell, F.; Mackey, J.R.; Costello, E.; et al. Pancreatic cancer hENT1 expression and survival from gemcitabine in patients from the ESPAC-3 trial. J. Natl. Cancer Inst. 2014, 106, e347. [CrossRef]

65. Sinn, M.; Budczies, J.; Damm, F.; Lohneis, P.; Schmuck, R.; Treue, D.; Striefler, J.K.; Bahra, M.; Pelzer, U.; Jühling, A. TP53 mutation predicts sensitivity to adjuvant gemcitabine in pancreatic cancer: Results from the CONKO-001 study. Ann. Oncol. 2017. [CrossRef]

66. Khorana, A.A.; Mangu, P.B.; Berlin, J.; Engebretson, A.; Hong, T.S.; Maitra, A.; Mohile, S.G.; Mumber, M.; Schulick, R.; Shapiro, M.; et al. Potentially curable pancreatic cancer: American society of clinical oncology clinical practice guideline. J. Clin. Oncol. 2016, 34, 2541-2556. [CrossRef]

67. Ducreux, M.; Cuhna, A.S.; Caramella, C.; Hollebecque, A.; Burtin, P.; Goéré, D.; Seufferlein, T.; Haustermans, K.; Van Laethem, J.L.; Conroy, T.; et al. Cancer of the pancreas: ESMO clinical practice guidelines for diagnosis, treatment and follow-up. Ann. Oncol. 2015, 26, 56-68. [CrossRef]

68. Palta, M.; Godfrey, D.; Goodman, K.A.; Hoffe, S.; Dawson, L.A.; Dessert, D.; Hall, W.A.; Herman, J.M.; Khorana, A.A.; Merchant, N.; et al. Radiation therapy for pancreatic cancer: Executive summary of an ASTRO clinical practice guideline. Pract. Radiat. Oncol. 2019, 9, 322-332. [CrossRef]

69. Cuneo, K.C.; Morgan, M.A.; Sahai, V.; Schipper, M.J.; Parsels, L.A.; Parsels, J.D.; Devasia, T.; Al-Hawaray, M.; Cho, C.S.; Nathan, H.; et al. Dose escalation trial of the wee1 inhibitor adavosertib (AZD1775) in combination with gemcitabine and radiation for patients with locally advanced pancreatic cancer. J. Clin. Oncol. 2019, 29, 2643-2650. [CrossRef] 
70. Uhl, W.; Ettrich, T.J.; Reinacher-Schick, A.C.; Algül, H.; Friess, H.; Kornmann, M.; Koenig, A.; Ghadimi, M.; Wittel, U.A.; Gallmeier, E. NEONAX trial: Neoadjuvant plus adjuvant or only adjuvant nab-paclitaxel plus gemcitabine for resectable pancreatic cancer, a phase II study of the AIO pancreatic cancer group (AIO-PAK-0313)—Safety interim analysis. J. Clin. Oncol. 2019, 37 (Suppl. 15), 4128. [CrossRef]

71. Unno, M.; Motoi, F.; Matsuyama, Y.; Satoi, S.; Matsumoto, I.; Aosasa, S.; Shirakawa, H.; Wada, K.; Fujii, T.; Yoshitomi, H. Randomized phase II/III trial of neoadjuvant chemotherapy with gemcitabine and S-1 versus upfront surgery for resectable pancreatic cancer (Prep-02/JSAP-05). J. Clin. Oncol. 2019, 37 (Suppl. 4), 189. [CrossRef]

(C) 2019 by the authors. Licensee MDPI, Basel, Switzerland. This article is an open access article distributed under the terms and conditions of the Creative Commons Attribution (CC BY) license (http://creativecommons.org/licenses/by/4.0/). 